\title{
Consumer Purchase Behaviour towards Foreign Made Ethnic Wear
}

\author{
Mohamed Basil ${ }^{1}$, Ramalakshmi ${ }^{2}$ \\ ${ }^{I}$ (Nottingham University Business School, The University of Nottingham in Malaysia, Malaysia) \\ ${ }^{2}$ (Srinivasa Ramanujan Centre, SASTRA University, India)
}

\begin{abstract}
The purpose of the study is to examine the Indian consumers purchase intention towards foreign made ethnic wear especially saris through the composite framework which includes variables like actual purchase and demographics. On other hand, the study aims to fulfil the scarcity in viewing 'foreign made' perspective of ethnic wears and also to contribute to the Indian consumer behaviour literature. A survey questionnaire was employed to derive data from 163 respondents who were identified through judgement sampling technique. The data were examined through SPSS 20.0. With some limitations, the variables had significance in explaining the results of overall model. On other hand, the results had shown that Indian consumers have positive attitude towards foreign made sari. The influence of variables has plethora of implications for both academic and managerial view.

Keywords: Attitude, Ethnic wear, Purchase behavior, Sari
\end{abstract}

\section{Introduction}

Wearing a dress is a complex ethnic identity and public issue in whole of Indian sub-continent which is highly varied between people of specific region, religion, caste and class (Hanson, 2004). Despite the differences, sari is considered to be the most commonly used costume with little variation among most Indian women (Banerjee and Miller, 2003). Saris are a strip of unstitched cloth, ranging from four to nine yards in length that is draped over the body in various styles (Boulanger, 1997). Though sari is a traditional ethnic wear crafted in the country for several centuries, the foreign influence on the ethnic wear is not new to the country. It can be noted as early as 1920 s, when Japan had strong tie-ups with Indian textile industry, it improvised to manufacture finer clothing from low quality cotton (Dietrich, 1929). Japan-made synthetic cheaper priced saris which are owned and distributed through Indian firms like Tata and Bajaj, had a positive response from Indian women which still exists in the market (Murthy, 2008).

Even though majority of products have foreign brands/ foreign made in the country and been flooded with either local or global players, it has to be noted that almost all product category has unorganised sectors (Batra et al., 2000). Especially, in niche markets like ethnic wears, the major players are still unbranded offerings which are locally made. But now, international brands have started to enter into ethnic wear market of India. Recently foreign brands like Hermes have started to sell French-made saris in India (Amy Kazmin, 2011) which has got greater attention in the Indian apparel market. On other hand, the invasion of Chinese saris also made the market to get more attention (CNN, 2012).

Moreover almost $26 \%$ of retail market is already dominated by women's ethnic wears (Mckinsey \& Company, 2008), where the fastest growing segments like saris, salwar-kameez and kurtis are valued to INR 363 Billion and projected to grow by 10\% during 2012-15 (RNCOS, 2012). On average, Indian consumers spend about approximately $6.51 \%$ of their total income on clothing items with expenditures on clothing increasing over the last three years (Gupta and Hodges, 2012). In fact, ethnic wear market is arguably growing faster than western wear market (Economic times, 2012). But the ethnic wear market is highly fragmented, unorganized and dominated by domestic players to a larger extent (Mckinsey \& Company, 2008).

To understand the consumers of ethnic wear market, this paper aims at highlighting the Indian consumer purchase behaviour towards foreign made ethnic wear. Specifically, the paper intends to identify the attributes, consequences and values that characterize consumer attitude and actual purchase. Their connections are studied through the comprehensive framework which rose from Jin and Kang's (2011) composite model.

\section{Literature Review}

The research on the attitude towards ethnic wear is primarily investigated from the point of view of acculturation (Rajagopalan and Heitmeyer, 2005) or ethnic identification (Chattaraman and Lennon, 2008) and results are focused on the question of their preference (Chen and Stanley, 1994; O'Neal, 1999; Chattaraman and Lennon, 2008; Rajagopalan and Heitmeyer, 2005; Kim and Arthur, 2003). But the studies on consumer attitudes 
towards foreign-made goods, especially in emerging ethnic wear markets like saris and how consumers evaluate their ethnic wear, i.e. attributes of foreign origin are relatively scarce.

Most of the researches are primarily focused on relationship between ethnic identity and ethnic apparels (Kim and Arthur, 2003; Chen and Stanley, 1994) or ethnic foods (Xu et al., 2004). Kim and Arthur (2003) conducted a study which focused on strength of ethnic identification among Asian American consumer's attitudes toward wearing, and ownership of ethnic apparel, in which, they postulate that consumers' ethnic or cultural identification strength has a significant impact on the consumption of ethnic and ethnic inspired apparels. A similar kind of study was conducted by Chattaraman and Lennon (2008) in connection with ethnic identity and consumption of ethnic apparels. The findings were consistent with previous study of Kim and Arthur (2003). The increasing acculturation to western culture has also made an impact on consumption of ethnic apparels especially on Asians and Africans. For example: O'Neal's (1999) study among African American professional women's motivations for the use of ethnic dress, found that African American women are either reluctant or in a dilemma to choose ethnic apparels or not. However, Chattaraman and Lennon (2008) emphasise that when the cultural setup are stronger and more structuralised like sari, which is treated as a formal dress in India, the ethnic apparels will be stronger enough to have edge in the market. Apparently, ethnic wears form one fourth of the whole retail apparel market (RNCOS, 2012).

A vast body of knowledge also coexists with regard to the attitudes involved in the purchasing foreign originated clothing, but scarce with reference to ethnic wears. The recent studies by Beaudoin, Ann Morre and Goldsmith (1998), Chan and Lau (1998), Knight (1999), Shen et al., (2003), Wang and Heitmeyer (2006), Phau and Leng (2008), Lee, Kumar and Kim (2010) and Bhardwaj, Kumar and Kim (2010) had made significant contribution to the foreign origin apparels literature. In India, a study was conducted to investigate consumer attitudes towards local and foreign brand names in general (Kinra, 2006). According to the study, foreign brands or foreign origin goods are generally perceived higher and superior to local brands in all attributes. The study also points that despite high level of nationalism and preference for indigenous manufacturer, Indian consumers are still in favour of foreign made goods. With reference to apparels, Lee, Kumar and Kim (2010) notes that Indian consumers did not perceive quality as a significant factor in affecting the purchasing intention of local brands. In the cognitive-affective model, they found that emotional value like prestige drives the purchase intention of Indian consumers.

In one way or the other, the above studies supports Batra et al's., (2000) generalization that almost all developing countries have high positive attitude towards non-local brands and imports. But such generalization has regulators like apparels attributes and demographic attributes. Jin, Park and Ryu (2009) give a comprehensive list of 13 apparel attributes: product, price, country/brand or origin, quality, design/style, fit, fibre/fabric, colour, care, brand name, comfort, durability, and fashion. Specifically, Jin, Park and Ryu (2009) note that attributes like price, country/brand of origin, quality, design/style, and fitting are more important than other. As identified from the studies (i.e. Beaudin, Moore and Goldsmith, 1998; and Wang and Heitmeyer, 2006), the attitude toward the foreign apparel varies according to the importance given to the apparel attribute by the individual. The degree of importance will vary in accordance to acculturation level, age, gender, fashion leaders, culture and familiarity with a product category (Jin, Park and Ryu, 2009). For example: (1) Country of Origin $(\mathrm{CoO})$ was identified as the most important factor in evaluating garments among U.S. consumers (Dickerson, 1982). But price was found to be most important among U.S. female consumers (Davis, 1987). (2) Young consumers rate design and country/brand origin with high priority (Dickson et al., 2004).

From the past literature it has been noted that both demographic and cultural variables will have significant influence in the apparel attribute variance. For example: Jin, Park and Ryu (2009) have suggested that the variation in the importance of apparel attributes can be explained by the gender variation. Similar to gender, in the context of the importance of apparels attribute. Past researches have noticed that age will also have sound impact on explaining the difference. Dickson et al., (2004) found that young consumers were most influenced by design and country/brand of origin attributes of apparels than elders. It implies that young consumers are more influenced towards status or prestige consumption than adults (Phau and Leng, 2008). Zhang et al., (2002) mentions that income, location, marital status and education will also have significance in apparel attribute preference.

\section{Theoretical Framework}

A composite form of three behavioural intention models i.e. the theory of reasoned action and the theory of planned behaviour, along with the Lee's modified Fishbein behavioural intention model is used as theoretical framework which was proposed by Jin and Kang (2011) for the study to examine the purchase intention of foreign made ethnic wear (saris) among Indian consumers. Jin and Kang's (2011) composite model will provide a platform to use all important constructs of previous models. Moreover, the model was statistically significant and proved to be valid in Asian context. 
FIGURE 1.1 Structure of Jin and Kang's (2011) composite model

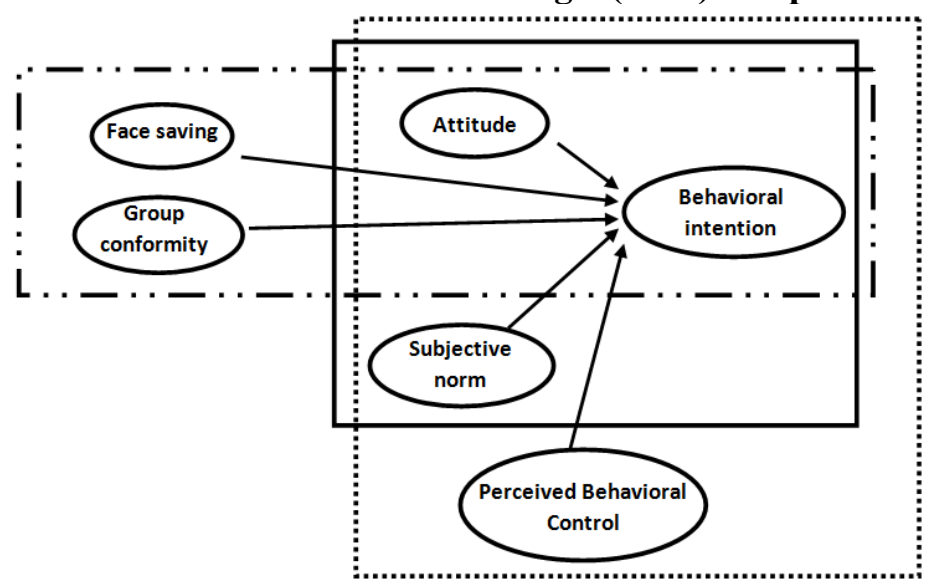

The Theory of Reasoned Action

— - - - - Lee's Modified Fishbein Behavioural Intention model

............. The Theory of Planned Behaviour

Based on the review, this study proposes a comprehensive framework and eight hypotheses. The proposed theoretical framework comprises of Jin and Kang's (2011) composite model along with actual purchase to enhance the predictability of the behaviour. In addition, as a part of study framework, demographic variables were also tested along with the base model. The Fig. 1.2 identifies the hypothesis that lead to the modified Indian consumer purchase behaviour towards ethnic apparels.

\section{FIGURE 1.2 - Proposed framework}

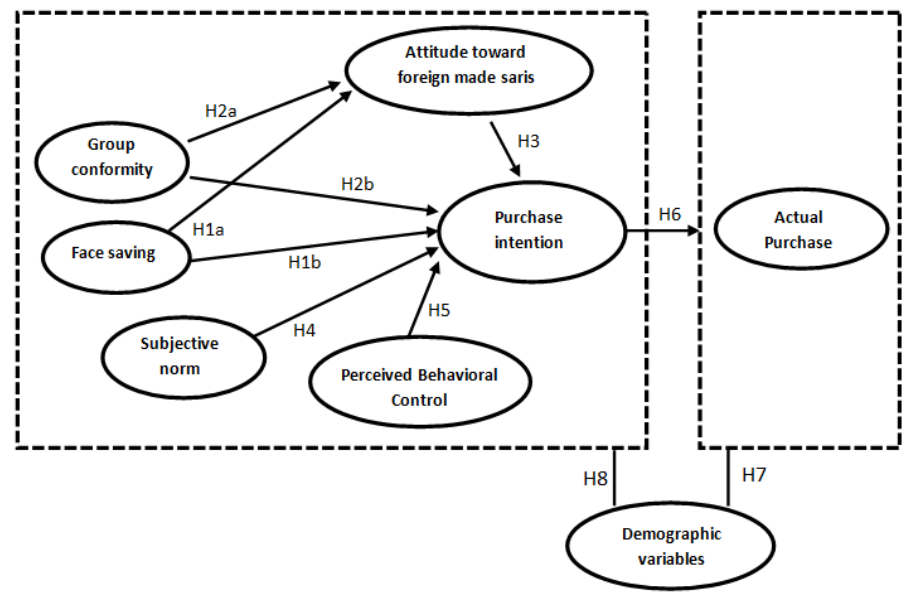

IV. Hypothesis

\subsection{Effect of face saving on attitude and purchase intention}

To define, face saving is one's position in his/her social system (Jin and Kang, 2011). Even though concept of 'face saving' seems to be parallel to western thoughts of prestige and dignity (Yau, 1986), it has much higher importance among collectivist societies (Hu and Grove, 1999). Chung and Pysarchik (2000) proved that face saving variable has influence on consumer attitude and purchase intention. The variable is proved to be significant contributor in major attitude studies conducted in collectivist societies of the world (Lee and Green, 1991; Lee, 1990). Irrespective of its unique people characteristics, most of studies in literature reported that Indian society is similar to most collectivist societies of Asia. Hence, the study proposes that face saving has influence on consumer attitude and purchase intention.

H1a: There is a positive relationship between face saving and attitude toward foreign made saris.

$\mathrm{H} 1 \mathrm{~b}$ : There is a positive relationship between face saving and purchase intention of foreign made saris.

\subsection{Effect of group conformity on attitude and purchase intention}

Group conformity is another type of social pressure which refers to complying with the group norm irrespective of individual's own view (Jin and Kang, 2011). Chung and Pysarchik (2000) and Malhotra and 
McCort (2001) noted that both face saving and group conformity have significant influence on consumer attitude and purchase intention. In terms of group conformity, India ranks higher as a collectivist society and having high social customs. Compared to west, group conformity in India is high and relatively more in-depth among other Asian countries. For example, most of the ethnic group people can be identified through their names which signal their high group conformity. Hence, the study proposes that group conformity has positive relationship with consumer attitude and purchase intention.

H2a: There is a positive relationship between the level of group conformity and attitude toward foreign made saris.

$\mathrm{H} 2 \mathrm{~b}$ : There is a positive relationship between the level of group conformity and purchase intention of foreign made saris.

\subsection{Effect of attitude and subjective norm on purchase intention}

The vast marketing literature supports that both, attitude toward a subject/product and subjective norm, influences purchase intention (Jin and Kang, 2011). In Indian context, Choo et al., (2004) found that attitude had direct impact on purchase intention. Moreover, being a highly stratified society, as observed from the Indian cultural setting, it is quite natural for anyone to assume that social structure and expectations i.e. subjective norms will have impact on purchase intention. Hence, the study hypothesised that both attitude and subjective norm will influence the purchase intention of foreign made saris among Indian consumers.

H3: There is a positive relationship between attitude and purchase intention for foreign made saris.

$\mathrm{H} 4$ : There is a positive relationship between subjective norm and purchase intention for foreign made saris.

\subsection{Effect of perceived behavioural control on purchase intention}

Ajzen (1991) proposed the concept of perceived behavioural control and revealed that it can produce a significant impact on behaviour. Perceived behavioural control includes control beliefs, or the belief on the resources and opportunities available to carry out the particular act or behaviour, and perceived facilitation, or the assessment of the importance of those resources to successfully complete the behaviour (Wiethoff, 2004). Studies had acknowledged that perceived behavioural control have positive significance on purchase intention (Kang et al., 2006). When it comes to Indian consumers, the studies are scarce in explaining perceived behavioural control. However, the study hypothesised that there is a positive relationship between perceived behavioural control and purchase intention towards foreign made saris.

H5: There is a positive relationship between perceived behavioural control and purchase intention of foreign made saris.

\subsection{Effect of purchase intention on actual purchase}

Young, DeSarbo and Morwitz (1998) identified the existence of positive relationship between actual purchase and purchase intention on durable goods. In contradictions, there are studies suggesting the partial satisfaction in using purchase intention as proxy to actual purchase. For example, Juster (1966) claimed that the number of consumers who indicated to purchase a car in next six months are reduced to half on actual purchase. Despite of contradictions, there is scarcity in solid model in explaining actual purchase and most researches in literature treats purchase intention as proxy to actual purchase. However, this study hypothesised that there is a positive relationship between actual purchase and purchase intention.

H6: There is a positive relationship between actual purchase and purchase intention of foreign made saris.

\subsection{Effect of demographic variables on actual purchase and antecedents of actual purchase}

In general, researchers had agreed that demographic changes influences consumer purchase behaviour (Wee et al., 1995). Previous studies had suggested that the demographic variables including gender, age, income and education have significant impact on purchase intention (Akhter, 2003). Zhang et al., (2002) noted that income, marital status and education will also have significance in purchase evaluation and behaviour. The researches on influence of gender (Rocha et al., 2005; Jin, Park, and Ryu, 2009), and age (Dickson et al., 2004) also claim the same results. The results are relatively similar in most contexts. For instance: demographic variables had shown significance in consumer purchase attitude towards software piracy (Solomon and O'Brien, 1991). Similarly, in apparel context, the roles of demographic variables are proven stronger in predicting the outcome (Zhang et al., 2002). Hence, this study hypothesises the following: 
H7: There is a relationship between demographic variables of consumers in India and their actual purchase towards foreign made saris.

H8: There is a relationship between demographic variables and the antecedents of actual purchase of foreign made saris viz., attitude, subjective norms, perceived behavioural control, and apparel purchase intention toward foreign made ethnic dress.

\section{Methodology}

Questionnaire survey was adopted to collect the data for the study and was completely developed in English. The questionnaire was personally administrated to the respondents. 'Sari' - most common Indian women's ethnic wear, was taken as the 'ethnic wear' of the study. Sari was selected for its better representation of whole contemporary Indian dresses (Banerjee and Miller, 2003). Even though there are several classifications of saris, the study focuses on synthetic casual and designer saris rather than silk or cotton.

The following TABLE 1.1 summarises the survey measurement of each constructs in the questionnaire:

TABLE: 1.1 - SURVEY MEASUREMENT

\begin{tabular}{|c|c|c|c|}
\hline Sec. & Measurement & Items & Reference \\
\hline 1 & Actual purchase & $\begin{array}{l}\text { 1. How many saris do you have in your wardrobe? } \\
\text { 2. How many of them are foreign made? }\end{array}$ & Developed by the researcher. \\
\hline 2 & $\begin{array}{l}\text { Importance of sari } \\
\text { attributes }\end{array}$ & $\begin{array}{l}\text { 1. Good fit 2. Durability 3. Ease of care } 4 \text {. Good price } 5 . \\
\text { Comfort } 6 \text {. Quality } 7 \text {. Choice of colour } 8 \text {. Attractiveness } 9 \text {. } \\
\text { Fashionableness } 10 \text {. Brand name } 11 \text {. Appropriateness for } \\
\text { occasion } 12 \text {. Choice of style } 13 \text {. Apparel fibre content } 14 \text {. } \\
\text { Country of origin }\end{array}$ & $\begin{array}{l}\text { Shim et al. (1989); } \\
\text { Wang and Heitmeyer (2006); } \\
\text { Jin, Park and Ryu (2009); Lee, } \\
\text { Kumar and Kim (2010); Shimp } \\
\text { and Sharma (1987) }\end{array}$ \\
\hline 3 & $\begin{array}{l}\text { Belief towards } \\
\text { foreign made sari }\end{array}$ & $\begin{array}{l}\text { 1. Good fit 2. Durability 3. Ease of care } 4 \text {. Good price } 5 . \\
\text { Comfort } 6 . \text { Quality } 7 \text {. Choice of colour } 8 \text {. Attractiveness } 9 . \\
\text { Fashionableness } 10 . \text { Brand name } 11 \text {. Appropriateness for } \\
\text { occasion } 12 \text {. Choice of style 13. Apparel fibre content } 14 \text {. } \\
\text { Country of origin }\end{array}$ & $\begin{array}{l}\text { Shim et al., (1989); } \\
\text { Wang and Heitmeyer (2006); } \\
\text { Jin, Park and Ryu (2009); Lee, } \\
\text { Kumar and Kim (2010); Shimp } \\
\text { and Sharma (1987) }\end{array}$ \\
\hline 4 & Subjective norm & $\begin{array}{l}\text { The importance of opinion in purchase of foreign made sari: - } \\
\text { Important friends - Parents - Siblings - Peers/ Colleagues }\end{array}$ & Shim et al., (2001) \\
\hline 5 & Purchase intention & $\begin{array}{l}\text { 1. I'll buy a foreign made sari in the near future. } 2 \text {. Whenever I } \\
\text { need to buy a sari, it is very likely that I'll purchase a foreign } \\
\text { made }\end{array}$ & Shim et al., (2001) \\
\hline 6 & $\begin{array}{l}\text { Perceived } \\
\text { behavioural control }\end{array}$ & $\begin{array}{l}\text { 1. It is very easy for me to buy a sari among many varieties } \\
\text { (i.e. local and foreign) available in the market. } 2 \text {. I have } \\
\text { resources (i.e. time and money) to buy a foreign made sari. }\end{array}$ & $\begin{array}{l}\text { Shim et al., (2001) } \\
\text { Jin and Kang (2011) }\end{array}$ \\
\hline 7 & Face saving & $\begin{array}{l}\text { My decision to buy a foreign sari would be influenced by: } 1 . \\
\text { Whether owing it would hurt my reputation with people who } \\
\text { are important to me. } 2 \text {. Whether I feel ashamed when people } \\
\text { who are important to me see me owing this product }\end{array}$ & $\begin{array}{l}\text { Lee (1990); Chung and } \\
\text { Pysarchik (2000) }\end{array}$ \\
\hline 8 & Group conformity & $\begin{array}{l}\text { 1. I feel that most people around me, expect me to comply with } \\
\text { their decision regarding a foreign made sari. } 2 \text {. My decision to } \\
\text { buy a foreign made sari would be influenced by owing it would } \\
\text { make me fit-in with other people. }\end{array}$ & $\begin{array}{l}\text { Lee (1990); Chung and } \\
\text { Pysarchik (2000) }\end{array}$ \\
\hline 9 & $\begin{array}{l}\text { Demographic } \\
\text { information }\end{array}$ & $\begin{array}{l}\text { Gender/ Age/ Monthly Income/ Location/ Average spending on } \\
\text { saris. }\end{array}$ & Developed by the researcher \\
\hline
\end{tabular}

A type of non-probability sampling method was adopted to select the respondents of the study. The judgement sampling technique was used to identify the respondents who were selected on the basis of information required (Sekaran, 2003) i.e. based on the representativeness of the population under study. The major reason to choose the technique was, in order to test the framework, the women consumers who wears sari are needed and should be from particular section of consumers who had knowledge on the subject.

The whole study was conducted in the district of Tamilnadu - a southern state of India. The respondents chosen for the study were college students, few higher secondary school students and academic staffs of a local high school, a university and a women's college. Particularly, a women's college in a semiurban area was chosen because it has a protocol for the students to wear saris as uniform in college. Other than that, a local university and a high school in urban area, which does not have such protocols, was selected for better distribution of population. Majority of respondents were females, as sari is meant only for females in Indian practice. However a small portion of sample size left to male respondents to have fair representativeness. Moreover, college students were selected for the purpose as the students were the main targets for foreign apparel firms (Batra et al., 2000). At those academic institutions, students and academic staffs were requested to fill out the questionnaires during their classes or intervals with the permission of higher authorities of the 
respective institutions. Each survey took almost $10-15$ minutes to complete. A total of 180 samples were collected. Due to high missing data 17 samples were rejected. Thereby, 163 usable data sets were entered for data analysis in SPSS 20.0

The majority of sample was taken from female respondents as sari is the ethnic wear for females, contributing to $87.1 \%$ of the sample and the male respondents are of $12.9 \%$. With respect to age, $61.3 \%$ of the sample belongs to the age group of 20 to 29. In addition, the age group of 15 to 19,30 to 39,40 to 49 and above 50 forms a total of $38.7 \%$ of the sample. The respondents of the study were derived from three major strata of location i.e. urban, semi-urban and rural contributing $30.7 \%, 44.2 \%$ and $25.1 \%$ respectively. Education level of the respondents was identified from the questionnaire where average numbers of respondents were either pursuing or holding a postgraduate degree contributing to $51.6 \%$ of the sample size. The minimum qualification was school level and the maximum was doctoral level. Majority of the respondents are single i.e. unmarried, totalling to $63.2 \%$ of the total sample and the married respondents were $36.8 \%$ of the sample. Almost a total of more than $75 \%$ of respondent's income level lies below INR 40,000 (Approx. USD 608.84*). The minimum income range falls below INR 20,000 (USD 304.42) and maximum income range falls between INR 80,001 to INR 1,00,000 (USD 1217.70 to USD 1522.10).

*Based on the currency values dated on 31/08/2013 where 1 INR $=0.015$ USD (source: http://www.xe.com)

The entire model was tested for fitness. Jin and Kang (2011) had already supported the fitness of the base model. However, as the actual purchase was added to the base model, the fitness indexes were revisited. It resulted with poor statistical significance. But, the model has shown acceptable statistical significance after the elimination of face saving variable as it had negative path coefficient and shown insignificant $p$ value $(p>0.05)$. Moreover, there was no much significant change in R-square before and after the elimination of face saving variable. It shows that it was the least predictor in the model. Nevertheless, hypotheses which included face saving variable were preceded by the hypothesis testing to support the elimination of the model. Other than that, model scale reliability, discriminant validity and correlations, which were assessed earlier, suggested the acceptable fitness of the model. The following TABLE 1.2 summarises the model fit indexes values.

TABLE 1.2: REGRESSION ANALYSIS FOR THE RESEARCH MODEL (AFTER FACE SAVING VARIABLE ELIMINATION)

\begin{tabular}{|c|c|c|c|c|c|}
\hline Model variables & $D f$ & F value & R Square & $\begin{array}{l}\text { Adjusted } \\
R \text { Square }\end{array}$ & $\begin{array}{l}\text { Path } \\
\text { coefficient } \beta \\
\text { value }\end{array}$ \\
\hline Dependent variable: & & & & & \\
\hline Attitude & 2 & 9.466 & 0.105 & 0.095 & \\
\hline Group conformity & & & & & $0.338^{*}$ \\
\hline Dependent variable: & 3 & 19.292 & 0.381 & 0.361 & \\
\hline Purchase intention & & & & & \\
\hline Group conformity & & & & & $0.297 *$ \\
\hline Attitude & & & & & $0.156^{* *}$ \\
\hline Subjective norm & & & & & $0.282 *$ \\
\hline Perceived Behavioural control & & & & & $0.001 * *$ \\
\hline $\begin{array}{l}\text { Dependent variable: } \\
\text { Actual purchase }\end{array}$ & 1 & 4.301 & 0.056 & 0.050 & \\
\hline Purchase intention & & & & & $0.161 * *$ \\
\hline
\end{tabular}

The standard regression analysis and bivariate correlations were used to test the proposed hypotheses. As identified in the model fitness, the relationship itself is found to be insignificant on hypothesis involving face saving variable i.e., hypothesis 1a and $1 \mathrm{~b}$ were not supported. However, the Hypotheses 2a, 2b, 3, 4, 5 and 6 were supported. In addition, hypothesis $7 \& 8$ were partially supported. There are many significant correlations found between demographic variables and antecedents of purchase intention. For instance, the location of the respondent had negative correlations with perceived behavioural control $(r=-0.162, p<0.05)$ and attitude $(r=-$ $0.230, \mathrm{p}<0.05)$; age of the respondent had significant correlations with perceived behavioural control $(\mathrm{r}=0.157$, $\mathrm{p}<0.05)$ and subjective norms $(\mathrm{r}=0.182, \mathrm{p}<0.05)$; and income level of the respondent had correlations with actual purchase $(\mathrm{r}=0.210, \mathrm{p}<0.05)$, purchase intention $(\mathrm{r}=0.199, \mathrm{p}<0.05)$ and group conformity $(\mathrm{r}=0.181$, $\mathrm{p}<0.05$ ). However, not all demographic variables had shown consistent relationship with antecedents of actual 
purchase. To re-ensure the above findings, multiple regressions were conducted which complies with the findings of bivariate correlations.

\section{Discussion And Conclusion}

From the data analysis, it was evident that face saving variable failed to explain the purchase behaviour of Indian consumers in the context of this study. It has to be noted that the face saving variable was first incorporated in the Fishbein model, for explaining the consumer behaviour in Confucian cultures like China and Korea. Even though, Confucian societies were characterised with high collectivism, strong uncertainty avoidance and larger power distance (Hofstede, 2001), it cannot be generalised to countries which are not mostly influenced by Confucian values. Even in Confucian cultures, the variable had performed with low significance. For example: In Chung and Pysarchik's (2000) study on Korean consumer behaviour intention to buy imported and domestic products, face saving variable had a weaker influence on attitude and purchase intention than other variables.

As consistent with previous studies, the findings supported Theory of Reasoned action and Theory of Planned behaviour by indicating that attitude, subjective norm and perceived behavioural control had shown significance in predicting purchase intention. To extent the results are consistent with previous studies. For example, the positive linkage between attitude and purchase intention results was similar to previous studies in literature like Shen et al., (2003) and Choo et al., (2004). However, the results show a slight difference of opinion with literature where group conformity $(\beta=0.297, p<0.01)$ gained more significance than attitude $(\beta=$ $0.156, p<0.01)$ in predicting purchase intention. It suggests that in general, group conformity can act as one of the most important variable in predicting the Indian consumer behaviour. It also implies that among two social pressure variables introduced by Lee (1990), group conformity alone works in predicting the purchase behaviour of Indian consumers in the study context.

As reflected from the above, face saving $((\beta=-0.024, p>0.05)$ did not have any significance on attitude as well, which complies with the previous studies in literature. However, as predicted, group conformity had high significance towards attitude, implying that attitude was shaped through group conformity of Indian consumers with reference to foreign made ethnic wear.

On the basis of sample taken in the study, the relationship between actual purchase and purchase intention was found to be positive. It adheres to past studies in literature like Young, DeSarbo and Morwitz, (1998). The predictable reason for the positive relationship can be: Sari is a mandatory costume in highly cultural influenced societies of the country; therefore people tend to use it to distinguish themselves among others as a sign of social prestige. As a highly stratified society, the sign of social prestige influences the consumers to show high favourability towards actual purchase of foreign made sari.

The other obvious reasons for the positive relationship between actual purchase and purchase intention toward foreign made sari are: On one hand, for longer period, foreign made goods were restricted in India. This control made those products scarce and expensive in the country which increased the symbolic values of foreign made goods. On the other hand, the continuous economic growth and increase in earning capacity of the consumers tends to purchase those goods irrespective of its price level. It can be identified from the lower significance level of perceived behavioural control than group conformity.

Moreover, in terms of attitude, consumers had shown high favourability towards foreign made saris in almost all criteria especially they ranked high for external attributes like quality, brand name, attractiveness and fashionablity. However when it comes to price, most consumer's belief was that foreign made saris are priced higher. The high favourability combined with social pressure and increased income level had resulted in the positive relationship between purchase intention and actual purchase.

In terms of demographic variables, as expected, income was the most significant predictor of actual purchase. It implies that income acts as a liaison between purchase intention and actual purchase where consumers with higher income reflected more on actual purchase and vice versa. This perhaps is because of consumer's belief that foreign made saris are expensive or overpriced and can be bought only those having sufficient income level or high status people. For instance, in this study, among total lower income group, only $38 \%$ reported the actual purchase of foreign made saris whereas the higher income group reported at $67 \%$. In other way, it can be concluded that the actual purchase increases when the consumers believe that they have sufficient financial means.

To add, interestingly, location had a negative effect with perceived behavioural control and attitude. It indicates that consumers in rural areas had much more positive attitude and had shown higher willingness towards foreign made sari than the urban consumers. Similarly, age factor had significant influence on both subjective norm and perceived behavioural control. In closer observation, it was found that the $75 \%$ of age group of above 50 had shown greater attachment towards subjective norm. Similarly, the 50+ age group had shown relatively high relationship with internal perceived behavioural control. The predictable reason for such 
specific relationship may be the elder consumers were more practiced in traditional hierarchical customs and expertise themselves in selecting saris than younger consumers.

\subsection{Academic implications}

This study contributes to the literature in two different dimensions. Primarily, other than the point of view of acculturation and ethnic identity, this study approaches ethnic wears from an alternative perspective i.e. on the basis of foreign made purchase intention. Thereby, it contributes the textiles and clothing research from a new dimension in approaching ethnic wears like saris. In another way, the context of ethnic wear was applied to the composite model of the study and contributed to the literature of purchase intention towards foreign made products.

Secondarily, the composite model of Jin and King (2011) along with demographic and actual purchase variables had been used in the study. The usages of such composite models in understanding consumer behaviour are relatively scarce in the Indian context. Hence, it has contributed to the existing body of knowledge from a new theoretical insight. As a by-product, this finding had shown (1) the relationship between the variables involved and identified the significance of each variable in overall model, (2) the important factors towards purchase intention in Indian context and (3) the importance of attribute in selecting an ethnic wear.

In addition, through identifying the positive relationship between purchase intention and actual purchase, this study also contributes to the literature regarding the influence of purchase intention on actual purchase (Nelson \& Devanathan, 2006; Young et al., 1998).

\subsection{Managerial implications}

Based on the results, as there was a direct relationship between intention and actual purchase, it was deliberately found that there is a keen interest among Indian consumers to purchase foreign made saris. Apart from that, with reference to the study results, the following suggestions can be made to the foreign companies who wish to expand their business to Indian ethnic wear market. The major implication which lies in the proper market segmentation based on the suggestions are listed below in two divisions:

First, in this study, group conformity and subjective norms work together more significantly in predicting the preference of ethnic wear. It shows that acceptability among the social groups is quite important. In order to gain more acceptances among the social groups, the trustworthiness of the product should be established. It can be developed though advertisements in print and television media as they are more effective tools in India (Srivastava, 2010; Terpstra \& Sarathy, 1997). In addition, in coherent with the study results, it suggests that product attributes influence the consumption behaviour and acceptability of the product. Therefore, the emphasis on positive product attributes such as quality, and traditional acceptability on advertisements through various media like TV shows, newspapers and magazines can improve the overall acceptability of the groups. To increase the acceptability, on the other side, product familiarity should be increased as it influences the attitude and intention Chung and Pysarchik (2000). Hence, foreign companies should increase their familiarity and their product knowledge including price to customers to be familiar as most consumers in the study perceived all foreign made saris are expensive.

Second, as income is the prime predictor of actual purchase, the price should be competitive with the local market, if the company wants to expand its business at all income tiers of consumers. The combination of attractive price and favourability can increase the frequency of purchase, as income is the major predictor of actual purchase. Also, there should be a caution exercised in fixing the price. If marketer fixes a premium costs, then it may decrease the external perceived control especially affordability and consumer will completely perceive the whole brand as 'out of their control'. On the other hand, the high affordability or cheaper price will lower the image of the product (Jin and Kang, 2011). Therefore, a compromise level between these two pricing strategies should be adopted like fixing a mid-premium price along with exclusive deals or promotions for frequent customers.

\subsection{Limitations and future research}

In data collection, non-probability judgement sampling technique was employed in the study. The data collected through judgement sampling cannot be generalizable (Sekaran, 2003). Hence, the study limits itself to the judgement samples chosen. In addition, India is a not a homogeneous country and even varies within the way of wearing the ethnic wear sari. In such context, the attribute preference can also change, within the demography of a country. As the study was conducted only in Tamilnadu, a southernmost state of India, the results can be applicable only to this specific region. Moreover, in terms of ethnic wear, other than saris, the study excluded other traditional men's wear like salwar-khameez and dhotis. So, the results cannot be generalized to whole ethnic wear purchase intention. In addition, there may be some possibilities that the use of comprehensive study framework along with the various other variables like level of acculturation can differ with current findings. 
As mentioned in the limitations, the future studies can attempt to use random sampling for better generalizability of results and include variables like cultural adherence, behavioural adoption and relevant variables to increase the validity and reliability of their findings. In future studies, the foreign made ethnic wear consumption can be approached from the perspective of triangulation where both quantitative and qualitative methodologies were used. It can bring in-depth meanings behind the numbers and words (Sekaran, 2003). Also, in other Indian contexts, many other ethnic wears are also under study. So, future studies can direct their attention towards those unique contexts. In addition, the future research model can be examined by using different statistical tools like Structural Equation modelling (SEM) which allows social and behavioural science researchers to empirically assess their theories (Pallant, 2010).

In case of unique ethnic wears, the attribute items should be well pooled from literature and could be given a pre-test to ensure its reliability. At last it will be interesting if the studies can be extended to consumer satisfaction response like fulfilment of hedonic and functional benefits attained from the purchase.

\section{Acknowledgement}

The author wish to express his gratitude to Ms. Anita Chakrabarty, Assistant Professor, The University of Nottingham, Malaysia campus for guiding the overall research; and Ms. Lalitha, Head of the commerce department, Adaikalamatha College - India for assisting in collecting the data..

\section{References}

[1] K. T. Hanson, The World in Dress: Anthropological Perspectives on Clothing, Fashion, and Culture. Annual Review of Anthropology, 33, 2004, 369-392.

[2] M. Banerjee and D. Miller, The Sari (Oxford: Berg Publishers, 2003).

[3] C. Boulanger, Saris: An Illustrated Guide to the Indian Art of Draping. (NY: Shakti Press International, 1997).

[4] E. Dietrich, Japan's Cotton Textile Industry. Barron's (1921-1942), 9 (5), 1929, 22.

[5] V. Murthy, Displaying Saris: Fashion Gallery of the National Museum of Singapore. The heritage journal , 3, 2008, 16-40

[6] R. Batra, D. Alden, J. Steenkamp, and S. Ramachander, Effects of brand local and nonlocal origin on consumer attitudes in developing countries. Journal of Consumer Psychology, 2000, 83-95.

[7] Amy Kazmin. (2011). Hermès sees sari as way in to India. [Online] Retrieved September 23, 2013, from FT.com: Available at: http://www.ft.com/cms/s/0/5c73d1b2-f0bf-11e0-aec8-00144feab49a.html\#axzz2fjuaiTWT

[8] CNN. (2012). Chinese saris threaten Indian tradition. [Online] Retrieved September 23, 2013, from Business.blogs.cnn.com: http://business.blogs.cnn.com/2012/02/09/chinese-saris-threaten-indian-tradition/

[9] Mckinsey \& Company,. The great Indian bazaar: Organized retail comes of age in India. (New Delhi: McKinsey \& Company, Inc., 2008).

[10] RNCOS, Indian Ethnic Wear Market for Women Showing Incredulous Growth. (Noida: RNCOS, 2012)

[11] M. Gupta, and N. Hodges, Corporate social responsibility in the apparel industry: An exploration of Indian consumers' perceptions and expectations. Journal of Fashion Marketing and Management , 16 (2), 2012, 216-233.

[12] Economic times (2012) Indian ethnic wears outsmart foreign brands in demand [Online] Retrieved May 08, 2012, from Economictimes.indiatimes.com: Available at: http://articles.economictimes.indiatimes.com/2012-03-13/news/31159684_1_salwarkameez-indian-market-saree-market

[13] B. Jin and J. Kang, Purchase intention of Chinese consumers toward a US apparel brand: a test of a composite behavior intention model. Journal of Consumer Marketing , 28 (3), 2011, 187 - 199.

[14] R. Rajagopalan and J. Heitmeyer, Ethnicity and consumer choice: A study of consumer levels of involvement in Indian ethnic apparel and contemporary American clothing. Journal of Fashion Marketing and Management , 9 (1), 2005,83 - 105.

[15] V. Chattaraman and S. J. Lennon, Ethnic identity, consumption of cultural apparel, and self-perceptions of ethnic consumers. Journal of Fashion Marketing and Management, 12 (4), 2008, 518-531.

[16] H. Chen and L. Stanley, Adaptation of Chinese design in Western contemporary dress. Perceptual and Motor Skills , 79, 1994, 7317 .

[17] G. O'Neal, African American women's professional dress as expression of ethnicity. The Meanings of Dress, $1999,388-93$.

[18] S. Kim and L. Arthur, Asian-American consumers in Hawaii: the effects of ethnic identification on attitudes toward and ownership of ethnic apparel, importance of product and store-display attributes, and purchase intention. Clothing and Textiles Research Journal , 21 (1), 2003, 8-18.

[19] Y. Xu, T. Summers and B. D. Belleau, Who buys American alligator? Predicting purchase intention of a controversial product. Journal of Business Research, 57, 2004, 1189-1198.

[20] P. Beaudoin, M. Ann Moore, and R. Goldsmith, Young fashion leaders' and followers' attitudes toward American and imported apparel. Journal of Product \& Brand Management, 7 (3), 1998, 193-207.

[21] R. Y. Chan, and L. Lau, A test of the Fishbein-Ajzen Behavioural Intentions Model under Chinese cultural settings: Are there any differences between PRC and Hong Kong consumers? . Journal of Marketing Practice: Applied Marketing Science , 4 (3), 1998, 85-101.

[22] G. A. Knight, Consumer preferences for foreign and domestic products. Journal of Consumer Marketing , 16 (2), 1999,151 - 162.

[23] D. Shen, M. A. Dickson, S. Lennon, C. Montalto, and L. Zhang, Cultural influences on Chinese consumers' intentions to purchase apparel: test and extension of the Fishbein behavioural intentional model. Clothing and Textile Research Journal , 21 (2), 2003, 8999.

[24] Y. Wang and J. Heitmeyer, Consumer attitude toward US versus domestic apparel in Taiwan. International Journal of Consumer Studies, 30 (1), 2006, 64-74.

[25] I. Phau and Y. Leng, Attitudes toward domestic and foreign luxury brand apparel: a comparison between status and non-status seeking teenagers. Journal of Fashion Marketing and Management , 12 (2), 2008, 68-89.

[26] H. J. Lee, A. Kumar, and Y. Kim, Indian consumers' brand equity toward a US and local apparel brand. Journal of Fashion Marketing and Management, 14 (3), 2010, 469-485. 
[27] V. Bhardwaj, A. Kumar, and Y. -K. Kim, Brand Analyses of U.S. Global and Local Brands in India: The Case of Levi's. Journal of global marketing, 23 (1), 2010.

[28] N. Kinra, The effect of country-of-origin on foreign brand names in the Indian market. Marketing Intelligence \& Planning , 24 (1), 2006, 15-30.

[29] B. Jin, J.Y. Park, and J. S. Ryu, Comparison of Chinese and Indian consumers' evaluative criteria when selecting denim jeans: A conjoint analysis. Journal of Fashion Marketing and Management , 14 (1), 2009, 180-194.

[30] K. Dickerson, Imported versus U.S.-produced apparel: Consumer views and buying patterns. Home Economics Research Journal , 10, 1982, 241-252.

[31] L. Davis, Consumer use of label information in ratings of clothing quality and clothing fashionability. Clothing and Textiles Research Journal , 6 (1), 1987, 8-14.

[32] M. Dickson, S. Lennon, C. Montalto, D. Shen, and L. Zhang, Chinese consumer market segments for foreign apparel products. Journal of Consumer Marketing , 21 (5), 2004, 301-17.

[33] L. Zhang, M. A. Dickson, and S. J. Lennon, S. J. The distribution channels for foreign-brand apparel in China: Structure, government's role, and problems. Clothing and Textiles Research Journal , 20, 2002, 167-180.

[34] O. H. Yau, Chinese cultural values and their marketing implications. Proc. of the Academy of International Business Southeast Asia Regional Conference, Taipei, National Chiao Tung University, 1986, 215-237.

[35] W. Hu, and C. Grove, Encountering the Chinese: A Guide for Americans (2nd ed.). (Yarmouth, ME: Intercultural Press, 1999).

[36] J. E. Chung, and D. T. Pysarchik, A model of behavioral intention to buy domestic versus imported products in a Confucian culture. Marketing Intelligence \& Planning , 18 (5), 2000, 281-291.

[37] C. Lee, and R. T. Green, Cross-cultural examination of the Fishbein behavioral intentions model. Journal of International Business Studies , 22 (2), 1991, 289-305.

[38] C. Lee, Modifying an American consumer behavior model for consumers in Confucian culture: the case of Fishbein behavioral intention model. Journal of International Consumer Marketing , 3 (1), 1990, 27-50.

[39] N. K. Malhotra, and J. D. McCort, A cross-cultural comparison of behavioral intention models: theoretical consideration and an empirical investigation. International Marketing Review , 18 (3), 2001, 235-269.

[40] H. Choo, J. E. Chung, and D. T. Pysarchik, Antecedents to new food product purchasing behaviour among innovator groups in India. European Journal of Marketing , 38 (5/6), 2004, 608-25.

[41] I. Ajzen, The Theory of Planned Behavior. Organizational Behavior and Human Decision Processes, 50, 1991, 179-211.

[42] C. Wiethoff. (2004). Motivation to learn and diversity training: Application of the theory of planned behavior. Human Resource Development Quarterly, 15 (3), 2004, 263-277.

[43] H. Kang, M. Hahn, D. R. Fortin, Y. J. Hyun, and Y. Eom, Effects of perceived behavioral control on the consumer usage intention of e-coupons. Psychology \& Marketing , 23 (10), 2006, 841-864.

[44] M.R. Young, W. S. DeSarbo, and V. G. Morwitz, The stochastic modelling of purchase intentions and behavior. Management Science, 44 (2), 1998, 188-202.

[45] F. T. Juster, Consumer Buying Intentions and Purchase Probability: An Experiment in Survey Design. Journal of the American Statistical Association , 61(315), 1966, 659-696.

[46] C.-H. Wee, S.-J. Ta, and K.-H. Cheok, Non-price determinants of intention to purchase counterfeit goods: an exploratory study. International Marketing Review , 12 (6), 1995, 19 - 46.

[47] S. Akhter, Digital Divide and Purchase Intention: Why Demographic Psychology Matters. Journal of Economic Psychology, 24(3), 2003, 321-327.

[48] M. A. Rocha, L. Hammond, and D. Hawkins, Age, gender and national factors in fashion consumption. Journal of Fashion Marketing and Management, 9 (4), 2005, 380 - 390.

[49] S. Solomon, and J. O’Brien, The effect of demographic factors on attitudes toward software piracy, in R. Dejoie, G. Fowler and D. Paradice (eds.), Ethical issues in information systems. (Boston: Boyd \& Fraser Publishing Company, 1991) 168-181.

[50] S. Shim, N. Morris, and G. Morgan, Attitudes toward imported and domestic apparel among college students: The Fishbein model and external variables. Clothing and textile research journal, 7 (4), 1989, 8-18.

[51] T. Shimp, and S. Sharma, Consumer ethnocentrism: construction and validation of the CETSCALE. Journal of Marketing Research , 24 (1), 1987, 280-289.

[52] S. Shim, M. Eastlick, S. Lotz, and P. Warrington, An online prepurchase intentions model: The role of intention to search. Journal of Retailing , 77(3), 2001, 397-416.

[53] V. Sekaran. Research methods for business: a skill-building approach. (New York: Wiley, 2003).

[54] G. Hofstede, Culture's Consequences (2nd ed.) (Thousand Oaks, CA: Sage, 2001).

[55] M. R. Nelson, and N. Devanathan, Brand placements Bollywood style. Journal of Consumer Behaviour , 5, 2006, 211-221.

[56] R. K. Srivastava, Effectiveness of global advertisement on culture of India: an emerging market. International Journal of Emerging Markets , 5 (1), 2010, 102-113.

[57] V. Terpstra, and R. Sarathy, International Marketing ( $7^{\text {th }}$ ed.) (Fort Worth, TX: The Dryden Press, 1997).

[58] J. Pallant, SPSS survival manual: a step by step guide to data analysis using SPSS (4th ed.) (Maidenhead: Open University Press/McGraw-Hill, 2010) 